\title{
Dichotomy of music in the approach of tension-type headache
}

\author{
Laura Santos Oliveira (iD) Natália de Fátima Gonçalves Amâncio \\ Medical School, University Center of Patos de Minas, Patos de Minas, Minas Gerais, Brazil
}

\section{$凶$}

Luana Santos Oliveira

laurasoliveira@unipam.edu.br

Edited by

Mario Fernando Prieto Peres

Marcelo Moraes Valença

\section{Keywords:}

Headache

Tension-type headache

Music

Music therapy

Severity

Alternative treatment.

\begin{abstract}
\section{Introduction}

Headache is one of the most frequent diseases of the nervous system. Headache is considered a public health problem, due to its high prevalence - since more than $90 \%$ of the population will present this clinical condition throughout their lives according to the World Health Organization (WHO) and for its negative impact on quality of life. In such a subtype of headache, music is seen as an antithesis either for its relief action or not, with findings in both extremes.

\section{Objective}

The objective of this paper is to identify the real effects of routine listening to music in patients with tension-type headache, based on reports in the current literature. The present study consists of an integrative literature review on the effects of routine listening to music in patients with tension-type headache.

\section{Methodology}

After careful reading of the publications, six articles were not used due to the exclusion criteria. Thus, 14 articles were selected for the final analysis and construction of the bibliographic review on the topic.

Results

After the analysis, in $50 \%$ of the studies, the intensity of the headache increased with listening to music, and in $50 \%$ of the studies the intensity of the headache with listening to music decreased.

\section{Conclusion}

It can be concluded that music is related in an ambivalent way to cases of headache arising from several etiologies. When administered at high frequencies, it can be a triggering factor, presenting a higher incidence in those who listen to it in this way, if compared to those who listen to it in a less intense way. But when used systematically, with frequency and delimited periods - such as the music therapy mechanism - music reveals itself as a beneficial element to reduce the frequency and intensity of headache caused by different diseases.
\end{abstract}




\section{Introduction}

- eadache is characterized as one of the most frequent diseases of the nervous system. ' For many authors, headache is considered a public health problem due to its high prevalence - since more than $90 \%$ of the population will present this clinical condition throughout their lives according to the World Health Organization (WHO) ${ }^{2,3}$ and for its negative impact on quality of life. ${ }^{4}$

Tension-type headache is one of the most recurrent types, given its triggers arising from daily stress. ${ }^{5}$ Tension-type headache affects two thirds of adult men and more than $80 \%$ of women. ${ }^{4}$ It can also be conceptualized as "constrictive headache, usually bilateral, with mild to moderate intensity, not aggravated by routine physical activities and with a variable duration between 30 minutes and 7 days". 6

In this sense, music is seen as an antithesis in the sense of its relief action or not, in such type of headache. Moreover, music is closely related to people at different times, not only as a social element, but also a professional one. ${ }^{7}$ Because of this, when music is heard with great frequency and intensity, it can bring irreversible damage to hearing, besides causing stress to the individual, with release of typical hormones such as cortisol, which can cause and/or intensify the occurrence of tension-type headaches. ${ }^{7}$

Still at this juncture, many studies have been developed regarding music therapy, in a non-pharmacological approach in the treatment of headaches. This mechanism is a complementary therapy based on the integration of listening to, producing, or composing music in the therapeutic process. ${ }^{8}$ It has thus been found that "classical music therapy can relieve the intensity of headache attack and reduce emotional stress". ${ }^{9}$ Since, according to the same authors, the effects of the intervention consist in the acceleration of cerebral blood flow, reducing the pressure in these vessels, starting from an interaction of hormones related to relaxation. Given the relevance of the topic in the current situation, both by the frequent incidence of headache, and the significance and scope of music at different times throughout life, the development of this work is based focusing on the relationship of the elements mentioned above. Thus, its development aims to identify the real effects of routine music listening in patients with tension-type headache, from reports in the current literature since the existing articles are not very enlightening when gathering the thresholds of music for the disease in question.

\section{Metodology}

The present study consists of an integrative literature review on the effects of routine listening to music in patients with tension-type headache. The PICO (acronym for Patient, Intervention, Comparison and Outcome) strategy was used to develop the research question of the integrative review. Thus, the defined research question was "Can people with tension-type headache have their symptoms changed by routinely listening to music? In it, we have $\mathrm{P}=$ People with tension-type headache; I= routine listening to music; and $\mathrm{O}=$ altered pictures. After establishing the search keywords, the descriptors "Tension Headache and Music"; "Tension Headache and Altered Charts"; "Music and Positive and Negative Effects and Headache"; "Music and Headache" were crossed in the following databases: Virtual Health Library (VHL); National Library of Medicine (PubMed MEDLINE), Scientific Electronic Library Online (SCIELO), and EbscoHost.

The search was conducted in the month of September 2020. Studies published between 2010 and 2020 were considered. The strategy for selection of articles followed the following steps: search of the selected databases; reading of the titles of all articles found and exclusion of those that did not address the subject; critical reading of the abstracts of the articles and full reading of the articles selected in the previous steps. Eighteen articles were found, of which the published titles and abstracts were read. Inclusion criteria were original articles that addressed the research topic and allowed full access to the study content; studies that did not meet the above inclusion criteria were excluded. After careful reading of the publications, six articles were not used due to the exclusion criteria. Thus, 12 articles were selected for the final analysis and construction of the literature review on the theme.

\section{Results and Discussion}

In study 1 (Table 1), $36 \%$ of adolescents who were exposed to listening to amplified music presented headache as an extra-auditory symptom, while in adolescents not exposed, $25 \%$ presented this symptom. However, these were not young people who had a clinical diagnosis of tension-type headache. ${ }^{10}$ In consonance, study 5 (Table 1) obtained similar results, in which 74 (62.20\%) of the amplified music listeners reported having headache, while $13(59.10 \%)$ of the non-users reported this symptom. ${ }^{13}$ Still regarding studies in which listening to music proved to be favorable to the occurrence of headache, when analyzing two groups of young people/ adults regarding the use of headphones in two distinct intensities - high and extended high - it was obtained that 29 of 182 participants who listened to music with high extended intensity, reported feeling headaches, while 7 of 46 who listened with high frequency reported this symptom. ${ }^{14}$ In study 2 (Table 1), 78 young patients with tension-type headaches were analyzed, who would receive the music therapy procedure over 8 weeks, being composed of two groups, one 
Table 1 - Analysis of the effects of music on patients with headache found in publications from 2013-2020

\begin{tabular}{|c|c|c|}
\hline Study & Title & Main Findings \\
\hline 1. Rodrigues ${ }^{10}$ & Hearing Evaluation in Adolescent Users of Amplified Music & $\begin{array}{l}\text { Increased frequency and } \\
\text { incidence of headaches }\end{array}$ \\
\hline 2. Koenig et al. ${ }^{11}$ & $\begin{array}{c}\text { Specific Music Therapy Techniques In The Treatment } \\
\text { Of Primary Headache Disorders In Adolescents: A Randomized } \\
\text { Attention-Placebo-Controlled Trial }\end{array}$ & Decrease in headache intensity \\
\hline 3.Purwandari, Yona ${ }^{9}$ & Classical Music Therapy As The Intervention To Relieve Headache In A Meningitis Patient & Decrease in headache intensity \\
\hline $\begin{array}{l}\text { 4. Siauta. Yusuf, } \\
\text { Suprajitno }\end{array}$ & $\begin{array}{c}\text { Change Of Blood Pressure And Headache In People With Hypertension } \\
\text { Using Relaxation Of Handgrip And Classical Music In Dr. M. } \\
\text { Haulussy Hospital Ambon }\end{array}$ & Decrease in headache intensity \\
\hline 5. Ferreira ${ }^{13}$ & Relationship of Listening Habits with Auditory and Extra-Auditory Symptoms in Adolescent Users of Amplified Music & $\begin{array}{l}\text { Increased frequency and } \\
\text { incidence of headaches. }\end{array}$ \\
\hline $\begin{array}{l}\text { 6. Sulaiman, Husain, } \\
\text { Seluakumaran }{ }^{14}\end{array}$ & $\begin{array}{c}\text { Hearing Risk among Young Personal Listening Device Users: Effects at High-Frequency and Extended High } \\
\text { Frequency Audiogram Thresholds }\end{array}$ & $\begin{array}{l}\text { Increased frequency and } \\
\text { incidence of headaches }\end{array}$ \\
\hline
\end{tabular}

Source: Research data, 2020.

that would receive any music therapy and the other with a pedagogical rhythm program and a "placebo control", the results were similar, and both groups obtained a moderate average reduction after treatment of $20 \%$ and a small portion obtained a $50 \%$ reduction of the symptom. ${ }^{11}$

In a more specific approach, it is revealed that classical music can be used in the context of headaches resulting from meningitis, which, despite not being the focus of this work, has similar effects on the brain region of the patient. ${ }^{9}$ Thus, a patient was exposed to classical music for 12 minutes and 15 seconds for 3 sessions over 3 days, obtaining positive results, relieving the intensity of pain, and reducing emotional stress. In the same way, when analyzing what was raised by Study 4 (Table 1), referring to the effects of classical music therapy against headache in hypertensive patients, it was shown to be advantageous, since all the groups that received the intervention had the intensity of the symptom reduced. ${ }^{12}$

After observing such studies, especially contemplating their methodologies and results, one can see that there are two distinct thresholds that correlate music to headache. The first would be the one in which music would be a trigger for headaches, as elucidated in studies 1, 5 and 6 (Table 1). However, it is relevant to emphasize that they were not focused on participants diagnosed with tension-type headache, and the big difference was the intensity in which the music was listened to, being in all of them with high intensity. ${ }^{10,13,14}$

The second one is about music as a non-pharmacological alternative for patients who have headache due to some pathology. Music therapy, in the analyzed studies, was used as an alternative for the relief of headache in patients with meningitis, with hypertension and in patients with primary headache, in all three, by means of correct tests, it was shown to be positive, regarding the reduction of headache intensity and frequency. Again, it is important to emphasize that the tests of the referred studies were not directed to patients with tension-type headache, thus becoming a factor for analogies, aiming at the physiological effect that music caused in both studies, dilating the encephalic vessels, and making the blood more fluid in this region. $9,11,12$

\section{Conclusion}

It can be concluded, from the content shown in this paper, that music is related in an ambivalent way to cases of headache arising from several etiologies. When administered at high frequencies, it can be a triggering factor, presenting a higher incidence in those who listen to it in this way, if compared to those who listen to it in a less intense way. But when used systematically, with frequency and delimited periods - such as the music therapy mechanism - music reveals itself as a beneficial element to reduce the frequency and intensity of headache caused by different diseases.

Therefore, it is important that new studies be developed, with the objective of relating music - with different styles, intensities, and frequency - to people who suffer from tension-type headache. Since the current literature has modest findings aiming at the effects of listening to music (this cultural and social manifestation) in a routine way, to this type of headache, which belongs to a vast portion of the national and world population.

\section{Financing: No \\ Conflict of interests: No}

Laura Santos Oliveira

https://orcid.org/0000-0002-6555-8465

Natália de Fátima Gonçalves Amâncio

https://orcid.org/0000-0003-4006-8619

\section{References}

1. Simić S, Rabi-Žikić T, Villar JR, et al. Impact of Individual Headache Types on the Work and Work Efficiency of Headache Sufferers. Int J Environ Res Public Health 2020;17(18) Doi: 10.3390/ijerph 17186918

2. Pinto DR, Morais J, Ferreira ASN, et al. Abordagem não-farmacológica na cefaleia do tipo tensional: efeitos da hidroterapia sobre a dor e a qualidade de vida. Revista Brasileira de Neurologia 2017;53(1):109-132 
3. Ramos DR. Composições Enfermas- Doença, crítica e música em Thomas Mann. Kriterion: Revista de Filosofia 2018;59:109-132

4. Faro P. Dia Nacional do Combate à Cefaleia - 19/05. 2017. Disponível em: https://sbcefaleia.com.br/noticias.php?id=321

5. Valença MM, Valença LPAA. Neuroarte e cefaleia: os enigmas nos afrescos de Michelangelo. Headache Medicine 2011;212-215 Doi: 10.48208/HeadacheMed.2011.32

6. Matta AP da C, Moreira Filho PF. Cefaléia do tipo tensional episódica: avaliação clínica de 50 pacientes. Arquivos de Neuro-Psiquiatria 2006;64:95-99 Doi: 10.1590/S0004-282X2006000100019

7. Lüders $D$, Gonçalves $C G$ de $O$, de Moreira Lacerda $A B$, et al. Music students: conventional hearing thresholds and at high frequencies. Brazilian Journal of Otorhinolaryngology 2014;80:296304 Doi: 10.1016/i.bjorl.2014.05.010

8. Rolle NMU, Carmo ALS do. Tratamento Profilático da cefaleia recorrente na infância. Jornal Paranaense de Pediatria 2020;21(1):5-13 Doi: 10.5935/1676-0166.20200003

9. Purwandari GM, Yona S. Classical Music Therapy as The Intervention to Relieve Headache in A Meningitis Patient. UIProceedings on Health. 2020;4(1):102-104 Doi: 10.7454/uiphm.v4i1.260
10. Rodrigues LB. Avaliação auditiva em adolescentes usuários de música amplificada. Mestrado em Ciências da Saúde. 2017.

1 1. Koenig J, Oelkers-Ax R, Kaess M, et al. Specific Music Therapy Techniques in the Treatment of Primary Headache Disorders in Adolescents: A Randomized Attention-Placebo-Controlled Trial. Journal Pain 2013; 14(10): 1 196-1207 Doi: 10.1016/i. ipain.2013.05.006

12. Siauta M, Yusuf A, Suprayitno. Change of Blood Pressure and Headache in people with Hypertension Using Relaxation of Handgrip and Classcical Music in Dr.M.Haulussy Hospital Ambon. Dama International Journal of Researchers 2017;2(5):3744

13. Ferreira JS. Relação dos hábitos com sintomas auditivos e extra-auditivos de adolescentes usuários de música amplificada. Bacharelado em Fonoaudiologia 2015.

14. Sulaiman AH, Husain R, Seluakumaran K. Hearing Risk among Young Personal Listening Device Users: Effects at High-Frequency and Extended High-Frequency Audiogram Thresholds. Journal of International Advanced Otology 2015; 1 1(2):Doi: 10.5152/iao.2015.699 